\title{
Oscillation and Asymptotic Behaviour of Solutions of Nonlinear Two-Dimensional Neutral Delay Difference Systems
}

\author{
K. Thangavelu, G. Saraswathi \\ Department of Mathematics, Pachaiyappa's College, Tamilnadu, India \\ Email: kthangavelu14@gmail.com,ganesan_saraswathi@yahoo.co.in
}

How to cite this paper: Thangavelu, K. and Saraswathi, G. (2017) Oscillation and Asymptotic Behaviour of Solutions of Nonlinear Two-Dimensional Neutral Delay Difference Systems. Journal of Applied Mathematics and Physics, 5, 1215-1221.

https://doi.org/10.4236/jamp.2017.56104

Received: February 21, 2017

Accepted: June 6, 2017

Published: June 9, 2017

Copyright (c) 2017 by authors and Scientific Research Publishing Inc. This work is licensed under the Creative Commons Attribution International License (CC BY 4.0). http://creativecommons.org/licenses/by/4.0/

\begin{abstract}
This paper deals with the some oscillation criteria for the two-dimensional neutral delay difference system of the form

$\Delta\left(x_{n}+p_{n} x_{n-k}\right)=b_{n} y_{n}, \Delta\left(y_{n}\right)=-a_{n} x_{n-l+1}, n \in \mathbb{N}\left(n_{0}\right)=1,2,3, \ldots$ Examples illustrating the results are inserted.
\end{abstract}

\section{Keywords}

Asymptotic, Two-Dimensional Neutral Delay Difference Systems

\section{Introduction}

Consider a nonlinear neutral type two-dimensional delay difference system of the form

$$
\begin{aligned}
& \Delta\left(x_{n}+p_{n} x_{n-k}\right)=b_{n} y_{n} \\
& \Delta\left(y_{n}\right)=-a_{n} x_{n-l+1}, \quad n \in \mathbb{N}\left(n_{0}\right)=1,2,3, \cdots
\end{aligned}
$$

Subject to the following conditions:

$\left(c_{1}\right),\left\{a_{n}\right\}$ and $\left\{b_{n}\right\}$ are nonnegative real sequences such that $\sum_{n=1}^{\infty} b_{n_{0}}=\infty$.

$\left(c_{2}\right),\left\{p_{n}\right\}$ is a positive real sequence.

$\left(c_{3}\right)$, f,g $: \mathbb{R} \rightarrow \mathbb{R}$ are continous non-decreasing with uf $(u)>0$, $u g(u)>0$, for $u \neq 0$ and $|f(u)| \geq k|u|$, where $k$ is a constant.

$\left(c_{4}\right), k$ and $l$ are nonnegative integers.

Let $\theta=\max \{k, 1\}$. By a solution of the system (1.1), we mean a real sequence $\left\{x_{n}, y_{n}\right\}$ which is defined for all $n \geq n_{0}-\theta$ and satisfies (1.1) for all $n \in \mathbb{N}\left(n_{0}\right)$. 
Let $W$ be the set of all solutions $X=\left\{x_{n}, y_{n}\right\}$ of the system (1.1) which exists for $n \in \mathbb{N}\left(n_{0}\right)$ and satisfies

$$
\sup \left\{\left|x_{n}\right|+\left|y_{n}\right| ; n \geq N\right\}>0 \text { for any integer } N \geq N_{0} .
$$

A real sequence defined on $\mathbb{N}\left(n_{0}\right)$ is said to be oscillatory if it is neither eventually positive nor eventually negative and nonoscillatory otherwise.

A solution $X \in W$ is said to be oscillatory if both components are oscillatory and it will be called nonoscillatory otherwise.

Some oscillation results for difference system (1.1) when $p_{n}=0$ for $n \in N\left(N_{0}\right)$ and $n-l+1=n$ have been presented in [1], In particular when $b_{n}>0$ for all $n \in N\left(n_{0}\right)$. The difference system (1.1) reduces to the second order nonlinear neutral difference equation

$$
\Delta\left(\frac{1}{b_{n}} \Delta\left(x_{n}+p_{n} x_{n-k}\right)\right)=-a_{n} x_{n-l+1} .
$$

If $b_{n}=1$, in Equation (1.2), we have a second order linear equation

$$
\Delta^{2}\left(x_{n}+p_{n} x_{n-k}\right)=-a_{n} x_{n-l+1} .
$$

For oscillation criteria regarding Equations (1.1)-(1.3), we refer to [2]-[12] and the references cited therein. In Section 2, we present some basic lemmas. In Section 3, we establish oscillation criteria for oscillation of all solutions of the system (1.1). Examples are given in Section 4 to illustrate our theorems.

\section{Some Basic Lemmas}

Denote $A_{n}=\sum_{s=n_{0}}^{n-1} a_{s}, n \in \mathbb{N}\left(n_{0}\right)$, For any $x_{n}$, we define $z_{n}$ by

$$
z_{n}=x_{n}+p_{n} x_{n-k}
$$

We begin with the following lemma.

2.1. Let $\left(c_{1}\right)-\left(c_{4}\right)$ hold and let $\left\{\left(x_{n}, y_{n}\right)\right\} \in W$ be a solution of system (1.1) with $\left\{x_{n}\right\}$ either eventually positive or eventually negative for $n \in \mathbb{N}\left(n_{0}\right)$. Then $\left\{\left(x_{n}, y_{n}\right)\right\}$ is nonoscillatory and $\left\{z_{n}\right\}$ and $\left\{y_{n}\right\}$ are monotone for $n \in \mathbb{N}(N)$ for $N \in \mathbb{N}\left(n_{0}\right)$.

Proof. Let $\left\{\left(x_{n}, y_{n}\right)\right\} \in W$ and let $\left\{x_{n}\right\}$ be nonoscillatory on $\mathbb{N}\left(n_{0}\right)$. Then from the second equation of system (1.1), we have $\Delta y_{n} \leq 0$ for all $n \geq N_{1} \in \mathbb{N}\left(n_{0}\right)$ and $\Delta y_{n}$, and $y_{n}$ are not identically zero for infinitely many values of $n$. Thus $\left\{y_{n}\right\}$ is monotone for $n \geq N$. Hence $\left\{y_{n}\right\}$ is either eventually positive or eventually negative for $n \geq N_{1}$. Then, $\left\{\left(x_{n}, y_{n}\right)\right\}$ is nonoscillatory. Further from the first equation of the system (1.1). We have $\Delta z_{n}>0$ or $\Delta z_{n}<0$ eventually. Hence $\left\{z_{n}\right\}$ is monotone and nonoscillatory for all $n \geq N \geq N_{1}$. The proof is similar when $\left\{x_{n}\right\}$ is eventually negative.

Lemma 2.2. In addition to conditions $\left(c_{1}\right)-\left(c_{2}\right)$ assume that $0<p_{n} \leq 1$ for all $n \in \mathbb{N}\left(n_{0}\right)$. Let $\left\{x_{n}\right\}$ be a nonoscillatory solution of the inequality

$$
x_{n}\left(x_{n}+p_{n} x_{n-k}\right) \geq 0
$$

for sufficiently large $n$. If for $n-k$ for all $n \in \mathbb{N}\left(n_{0}\right)$. Then, $\left\{x_{n}\right\}$ is bounded.

Proof. Without loss of generality we may assume that $\left\{x_{n}\right\}$ be an eventually 
positive solution of the inequality (2.1), the proof for the case $\left\{x_{n}\right\}$ eventually negative is similar. From (2.1) we have

$$
\left(x_{n}+p_{n} x_{n-k}\right) \geq 0, \text { for } n \geq \mathbb{N}\left(n_{0}\right) .
$$

and $0<p_{n} \leq 1$, we have from (2.2), $x_{n-k} \leq p_{n} x_{n-k} \leq x_{n}$ for all $n \geq N$. Hence $\left\{x_{n}\right\}$ is bounded.

Next, we state a lemma whose proof can be found in [1].

Lemma 2.3. Assume that $\left\{a_{n}\right\}$ is a non negative real sequence and not identically zero for infinitely many values of $\mathrm{n}$ and $\mathrm{l}$ is a positive integer. If

$$
\liminf _{n \rightarrow \infty} \sum_{s=n-l+1}^{n-1} a_{s}>\left(\frac{l}{l+1}\right)^{l+1}
$$

Then the difference inequality

$$
\Delta y_{n}+a_{n} x_{n-l+1} \leq 0 \quad n \in \mathbb{N}\left(n_{0}\right)
$$

cannot have an eventually positive solution and

$$
\Delta y_{n}+a_{n} x_{n-l+1} \geq 0 \quad n \in \mathbb{N}\left(n_{0}\right)
$$

cannot have an eventually negative solution.

\section{Oscillation Theorems for the System (1.1)}

Theorem 3.1. Assume that $\left\{p_{n}\right\}$ is bounded and there exists an integer $j$ such that $l>j+k+2$. If

$$
\limsup _{n \rightarrow \infty} A_{n} \sum_{s=n-l+1}^{\infty} a_{s}>\frac{1}{k \beta}
$$

and

$$
\liminf _{n \rightarrow \infty} \sum_{s=n-(l-j-k)}^{n-1} k \beta b_{s}\left(\sum_{t=s}^{s+j} \frac{a_{t}}{p_{t-l+k+1}}\right)>\left(\frac{l-j-k}{l-j-k+2}\right)^{l-j-k+2}
$$

Then every solution $\left\{\left(x_{n}, y_{n}\right)\right\} \in W$ is a nonoscillatory solution of system (1.1), with $\left\{x_{n}\right\}$ bounded. Without loss of generality we may assume that $\left\{x_{n}\right\}$ is eventually positive and bounded for all $n \geq n_{1} \in N\left(n_{0}\right)$. From the second equation of (1.1), we obtain $\Delta y_{n} \leq 0$ for sufficiently large $n \geq n_{2} \in N\left(n_{1}\right)$. In view of Lemma 2.1 , we have two cases for sufficiently large $n_{3} \in N\left(n_{2}\right)$ :

1) $y_{n}<0$ for $n \geq n_{3}$;

2) $y_{n}>0$ for $n \geq n_{3}$.

Case (1). Because $\left\{y_{n}\right\}$ is negative and nonincreasing there is constant $L>0$. Such that

$$
y_{n} \leq-L \text { for all } \mathrm{n} \geq n_{3}
$$

Since $\left\{x_{n}\right\}$ and $\left\{p_{n}\right\}$ are bounded. $\left\{z_{n}\right\}$ defined by (2.1) is bounded. Summing the first equation of (1.1) from $n_{3}$ to $n-1$ and then using (3.3), we obtain

$$
z_{n}-z_{n_{0}} \leq-L \sum_{s=n_{3}}^{n-1} a_{s}, \quad n \geq n_{3} .
$$

From (3.3), we see that $\lim _{n \rightarrow \infty} z_{n}=-\infty$ which contradicts the fact that $\left\{z_{n}\right\}$ 
is bounded. Case (1) cannot occur.

Case (2). Let $z_{n}>0$ for $n \geq n_{4}$ where $n_{4} \in N\left(n_{3}\right)$ is sufficiently large. Because $\left\{z_{n}\right\}$ is nondecreasing there is a positive constant $M$, such that

$$
z_{n} \geq M \text {, for all } n \geq n_{4} \text {. }
$$

From (2.1), we have $z_{n}>x_{n}$, and by hypothesis, we obtain

$$
a_{n} Z_{n-l+1} \geq a_{n} \frac{x_{n-l+1}}{k}, \quad n \geq n_{5} \in N\left(n_{4}\right)
$$

summing the second equation of (1.1) from $n$ to $i$, using (3.5) and then letting $i \rightarrow \infty$, we obtain

$$
y_{n} \geq k \sum_{s=n}^{\infty} a_{s} z_{s-l+1}, \quad n \geq n_{5} .
$$

From condition (3.1), we have

$$
\frac{1}{k \beta}<\limsup _{n \rightarrow \infty} A_{s} a_{s}
$$

we claim that the condition (3.1) implies

$$
\sum_{n=N}^{\infty} A_{n} a_{n}=\infty, \quad N \in N\left(n_{0}\right) .
$$

Otherwise, if $\sum_{n=N}^{\infty} A_{n} a_{n}<\infty$, we can choose an integer $N_{1} \geq N$. So large that $\sum_{n=N_{1}}^{\infty} A_{n} a_{n}<\frac{1}{k \beta}$ which contradicts (3.6).

Using a summation by parts formula, we have

$$
\sum_{s=N}^{n-1} A_{s+1} \Delta g\left(y_{s}\right)=A_{n} y_{n}-A_{N} y_{N}-z_{n}-z_{N} .
$$

From (3.3), (3.4) and (3.6) and the second equation of (1.1), we have

$$
\begin{aligned}
& \sum_{s=N}^{n-1} A_{s+1} \Delta g\left(y_{s}\right) \leq \beta \sum_{s=N}^{n-1} A_{s+1} \Delta y_{s} \\
& \leq-M k \beta \sum_{s=N}^{n-1} A_{s+1} y_{s} \\
& \leq-M k \beta \sum_{s=N}^{n-1} A_{s} y_{s} \\
& M k \beta \sum_{s=N}^{n-1} A_{s} y_{s}=-A_{n} y_{n}+A_{N} y_{N}+z_{n}-z_{N}, n \geq N .
\end{aligned}
$$

combining (3.6) with (3.8), we obtain

$$
\lim _{n \rightarrow \infty}\left(z_{n}-A_{n} y_{n}\right)=\infty
$$

and

$$
z_{n} \geq A_{n} g\left(y_{n}\right) \geq \beta A_{n} y_{n}, \quad n \geq n_{6} \in \mathbb{N}\left(n_{5}\right) .
$$

The last inequality together with (3.4) and the monotonocity of $\left\{z_{n}\right\}$ implies

$$
\begin{aligned}
z_{n} & \geq k \beta A_{n} \sum_{s=n}^{\infty} a_{s} z_{s-l+1} \geq k \beta A_{n} \sum_{s=n-l+1}^{\infty} a_{s} z_{s-l+1} \\
& \geq k \beta A_{n} z_{n} \sum_{s=n+l-1}^{\infty} a_{s}
\end{aligned}
$$


and $1 \geq k \beta A_{n} z_{n} \sum_{s=n+l-1}^{\infty} a_{s}, \quad n \in \mathbb{N}\left(n_{6}\right)$ which contradicts (1.1). This case cannot occur. The proof is complete.

Theorem 3.2. Assume that $0<p_{n} \leq 1$, then there exists an integer $j$ such that $l>j+k$ and the conditions (3.1) and (3.2) are satisfied. Then all solutions of (1.1) are oscillatory.

Proof. Let $\left\{\left(x_{n}, y_{n}\right)\right\} \in W$ be a nonoscillatory solution of (1.1). Without loss of generality we may assume that $\left\{x_{n}\right\}$ is positive for $\mathrm{n} n \in \mathbb{N}\left(n_{1}\right)$. As in the proof of above theorem we have two cases.

Case (1). Analogus to the proof of case (1) of above theorem, we can show that $\lim _{n \rightarrow \infty} z_{n}=-\infty$. By Lemma 2.2, $\left\{x_{n}\right\}$ is bounded and hence $\left\{z_{n}\right\}$ is bounded which is a contradiction. Hence case (1) cannot occur.

Case (2). The proof of case (2) is similar to that of the above theorem and hence the details are omitted. The proof is now complete.

Theorem 3.3. Assume that $0<p_{n} \leq 1$ and

$$
\begin{gathered}
\operatorname{lim\operatorname {sup}_{n\rightarrow \infty }} \sum_{s=n-k-l+1}^{n-1} \frac{k \beta\left(A_{n}-A_{s+1}\right)}{p_{s-l-k+1}} a_{s}>1 . \\
\sum_{n=N}^{\infty} b_{n}\left(\sum_{s=n}^{\infty} a_{s}\right)=\infty, \quad N \in N\left(n_{0}\right) \\
\lim _{n \rightarrow \infty} \sup \left(k \beta A_{n} \sum_{s=n}^{\infty} a_{s}\right)>1 .
\end{gathered}
$$

Then all solutions of (1.1) are oscillatory.

Proof. Let $\left\{\left(x_{n}, y_{n}\right)\right\} \in W$ be a nonoscillatory solution of (1.1). Without loss of generality we may assume that $\left\{x_{n}\right\}$ is positive for $n \in \mathbb{N}\left(n_{1}\right)$. As in the proof of above theorem we have two cases.

Case 1. From (2.1), we have

$$
z_{n}>p_{n} x_{n-k}, \quad n \geq n_{3} \in N\left(n_{0}\right)
$$

and

$$
f\left(x_{n-l+1}\right) \geq k x_{n-l+1}>k \frac{Z_{n-l-k+1}}{p_{n-l-k+1}}, \quad n \geq n_{4}
$$

where $n_{4} \in N\left(n_{3}\right)$ is sufficiently large. Then the following equality

$$
\begin{gathered}
z_{n}=z_{i}+\left(A_{n}-A_{i}\right) y_{i}+\sum_{s=i}^{n-1}\left(A_{n}-A_{s+1}\right) \Delta y_{s} \\
z_{n}<\sum_{s=i}^{n-1}\left(A_{n}-A_{s+1}\right) \Delta y_{s}, \quad n>i \geq n_{5} .
\end{gathered}
$$

Combining the last inequality with the second equations of (1.1) and (3.17), we have

$$
\begin{aligned}
Z_{n} & <\beta \sum_{s=i}^{n-1}\left(A_{n}-A_{s+1}\right)\left(-a_{s} f\left(x_{s-l}\right)\right) \\
& <k \beta \frac{\sum_{s=i}^{n-1}\left(A_{n}-A_{s+1}\right) a_{s} Z_{s-l-k+1}}{p_{s-l-k+1}}, n>i \geq n_{5} .
\end{aligned}
$$

Let $i=n-l+k+1$ and using the monotonocity of $\left\{z_{n}\right\}$, from the last inequality, we obtain 


$$
z_{n}<z_{n} \sum_{s=n-l-k+1}^{n-1} k \beta \frac{\left(A_{n}-A_{s+1}\right) a_{s}}{p_{s+l+k-1}}
$$

and

$$
1>z_{n} \sum_{s=n-l-k+1}^{n-1} k \beta \frac{\left(A_{n}-A_{s+1}\right) a_{s}}{p_{s+l+k-1}}
$$

which contradicts the condition (3.14).

Case 2. The proof for this case is similar to that of Theorem (3.1). Here we use condition (3.16) instead of condition (2.1). The proof is complete.

\section{Examples}

Example 4.1. Consider the difference system

$$
\begin{aligned}
& \Delta\left(x_{n}+\frac{1}{2} x_{n-3}\right)=\frac{1}{n} y_{n} \\
& \Delta y_{n}=-n x_{n-2}, n \geq 1 .
\end{aligned}
$$

The conditions (3.1) and (3.2) are

$$
\begin{gathered}
\limsup _{n \rightarrow \infty} \frac{1}{n} \sum_{s=n+2}^{\infty} s=\infty . \\
\liminf _{n \rightarrow \infty} \sum_{s=n-4}^{n-3} \frac{1}{s}\left(\sum_{t=s-1}^{s} 2 t\right)=4 .
\end{gathered}
$$

All conditions of Theorem 3.2 are satisfied and so all solutions of the system (4.1) are oscillatory.

Example 4.2. Consider the difference systems

$$
\begin{aligned}
& \Delta\left(x_{n}+\frac{1}{4} x_{n-2}\right)=(n+1) y_{n} \\
& \Delta y_{n}=\frac{-c}{n+1} x_{n-1}, n \geq 1,
\end{aligned}
$$

where $c$ is a positive constant. The conditions (3.1) and (3.2) are

$$
\lim _{n \rightarrow \infty} \sup (n+1) \sum_{s=n+1}^{\infty} \frac{c}{s+1}=\infty
$$

and

$$
\liminf _{n \rightarrow \infty} \sum_{s=n-3}^{n-2}(s+1)\left(\sum_{t=s}^{s+1} \frac{-4 c}{t+1}\right)=12 c
$$

For $c>\frac{1}{12}$, all conditions of Theorem 3.2 are satisfied and so all solutions of the system (4.2) are oscillatory.

\section{References}

[1] Agarwal, R.P. (2000) Difference Equations and Inequalities. 2nd Edition, Marcel Dekkar, New York.

[2] Elizebeth, S., Graef, J.R., Sundaram, P. and Thandapani, E. (2005) Classifying Nonoscillatory Solutions and Oscillations of Neutral Difference Equations. Journal of Difference Equations and Applications, 11, 605-618. 
https://doi.org/10.1080/10236190412331334491

[3] Sternal, A. and Szamanda, B. (1996) Asymptotic and Oscillatory Behaviour of Certain Difference Equations. Le Matematiche, 51, 77-86.

[4] Sternal, A., Szamanda, B. and Szafranski, Z. (1998) Oscillatory and Asymptotic Behaviour of Some Difference Equations. Publications. DE L'INSTITUT MATHEMATQUE, 63, 66-74.

[5] Thandapani, E. (1992) Asymptotic and Oscillatory Behaviour of Solutions of a Second Order Neutral Difference Equations. Riv. Mat. Univ. Parma, 1, 105-113.

[6] Thandapani, E. and Mahalingam, K. (2003) Necessary and Sufficient Condition for Oscillation of Second Order Neutral Difference Equations. Tamkang Journal of Mathematics, 34, 137-145.

[7] Thandapani, E. and Mohankumar, P. (2007) Oscillation of Difference Systems of the Neutral type. Computers and Mathematics with Applications, 54, 556-566. https://doi.org/10.1016/j.camwa.2006.12.029

[8] Thandapani, E., Sundaram, P., Graef, J.R. and Spikes, P.W. (1995) Asymptotic Properties of Solutions of Nonlinear Second Order Neutral Delay Difference Equations. Dynam. Systems Appl., 4, 125-136.

[9] Thandapani, E. and Sundaram, P. (2000) Oscillation and Nonoscillation Theorems for Second Order Quasilinear Functional Difference Equations. Indian J. Pure Appl. Math, 31, 37-47.

[10] Zhang, B.G. and Saker, S.H. (2003) Kamenev-Type Oscillation Criteria for Nonlinear Neutral Delay Difference Equations. Indian J. Pure Appl. Math., 34, 15711584.

[11] Zhang, G. (2002) Oscillation for Nonlinear Neutral Difference Equations. Applied Math. E-Notes, 2, 22-24.

[12] Zhang, Z., Chen, J. and Zhang, C. (2001) Oscillation of Solutions of Second Order Nonlinear Difference Equations with Nonlinear Neutral Term. Computers and Mathematics with Applications, 41, 1571-1584.

https://doi.org/10.1016/s0898-1221(01)00113-4

\section{Scientific Research Publishing \\ Submit or recommend next manuscript to SCIRP and we will provide best service for you:}

Accepting pre-submission inquiries through Email, Facebook, LinkedIn, Twitter, etc. A wide selection of journals (inclusive of 9 subjects, more than 200 journals)

Providing 24-hour high-quality service

User-friendly online submission system

Fair and swift peer-review system

Efficient typesetting and proofreading procedure

Display of the result of downloads and visits, as well as the number of cited articles

Maximum dissemination of your research work

Submit your manuscript at: http://papersubmission.scirp.org/

Or contact jamp@scirp.org 